\title{
Second-Best Congestion Pricing in Urban Space: Cordon Pricing and Its Alternatives
}

\author{
TAKAMASA AKIYAMA \\ Department of Civil Engineering, Gifu University \\ SE-IL MUN * \\ Graduate School of Economics, Kyoto University \\ MASASHI OKUSHIMA \\ Department of Civil Engineering, Gifu University
}

\begin{abstract}
This paper examines the effects of alternative congestion pricing systems, cordon pricing and congestion pricing for existing toll roads, using the network equilibrium model developed for the Osaka Metropolitan Area, Japan. Cordon pricing is more effective in reducing the total efficiency loss from traffic congestion, but produces relatively large amounts of toll revenue. On the other hand, pricing for existing toll roads keeps the loss in consumer surplus (and toll revenue) relatively low to attain the same level of efficiency gain as the cordon pricing.
\end{abstract}

\section{Introduction}

Road pricing is now considered as practical policy instrument for controlling traffic congestion, following successful implementations in Singapore, Norwegian cities and London. This has stimulated research on congestion pricing in more realistic settings than earlier research in this field. Notable developments in recent years include the analysis of second-best pricing in space, where trips generate from many locations and congestion levels vary across space.

The spatial settings in the previous studies are classified into networks and continuous space. The majority are network models, which have been applied to actual cities for empirical estimation. May et al. (2000) applied a network simulation model of the city of

\footnotetext{
* Corresponding author. Graduate School of Economics, Kyoto University, Yoshida Hon-machi, Sakyo-ku, Kyoto 606-8501, JAPAN, E-mail: mun@econ.kyoto-u.ac.jp We thank Takayuki Suyama for helping with computing. This research was partially supported by the Ministry of Education, Culture, Sports, Science and Technology (MEXT), Grant-in-Aid for Scientific Research (No. 13630008, 13851002) and for 21st Century COE Program "Interfaces for Advanced Economic Analysis."
} 
Cambridge, U. K., to compute the effects of alternative pricing systems such as cordon pricing, distance-based, congestion-based, etc. They mainly focused on changes in spatial patterns of traffic flow and congestion, and the level of economic welfare was not discussed in detail. Santos, et al. (2001) used a similar network simulation model to obtain the optimal cordon tolls for eight English towns. On the other hand, Verhoef (2002), Zhang and Yang (2004), Sumalee (2004) discussed the mathematical problem of obtaining optimal choices of toll levels and locations of toll collection in a network. They mainly focused on methods of computing optimal solutions, and presented the numerical results for testing the methods. Although network models are useful for practical applications, they are not suitable for investigating the general properties of the problem, since the results depend on the network structures specified for calculations. On the other hand, the continuous space models are useful for theoretical analysis on qualitative properties of traffic pattern and resource allocation under alternative pricing systems. Mun, Konishi, Yoshikawa (2003a) present a model that explicitly deals with the spatial patterns of trip making behavior and traffic congestion in continuous one-dimensional space. They examined the effect of cordon pricing in a mono-centric city where all trips are destined to the $\mathrm{CBD}$, and showed that cordon pricing attains an economic welfare level very close to the first-best optimum. This finding is supported by Ho, Wong, Yang, Loo (2003) for two-dimensional space. However, Mun, Konishi, Yoshikawa (2003b) discusses that the above finding depends on the assumption of mono-centric city. They showed that the gains of cordon pricing tend to be large if the urban spatial structure is close to monocentric; density gradient is steeper; trip demand is less elastic; road capacity is larger. This suggests that cordon pricing tends to be effective in smaller cities. If the costs for installation of the pricing system are incorporated, the net benefit of cordon pricing in large cities is more likely to be small.

Most studies so far have focused on the system of cordon pricing, which is most popular in practice. This paper deals with an alternative policy, introducing congestion pricing on existing toll roads, which carry a large share of traffic in Japanese metropolitan areas, Tokyo and Osaka. It is a promising policy alternative for the following reasons. First, resistance toward introduction of congestion pricing for existing toll roads is expected to be much less than that toward cordon pricing: people understand that those roads are already tolled. As suggested by the experience in London, introduction of cordon pricing requires a lot of time and effort to attain public acceptance. Since discussions about road pricing have not matured in Japan, the introduction of cordon pricing in the near future would be unthinkable. Changes in the level of charges for existing tolled roads are much more easily accepted than the introduction of tolling at previously un-tolled roads. Furthermore, leaving un-tolled options for drivers may be essential to reduce objections: drivers can avoid toll payments by choosing un-tolled roads under this system while they cannot avoid payment under cordon pricing. Second, the cost of implementing changes in the level of charges of the tolling system would be much lower since existing facilities for monitoring traffic and collecting tolls can be used with minor modifications. Furthermore, the Electronic Toll Collection (ETC) system is under construction and is expected to be available in a few years for use on Japanese urban expressways.

This paper examines both cordon pricing and congestion pricing on existing toll roads, and compares their relative performance. Our analysis is based on the network model developed for Osaka Metropolitan Area in Japan, since it is necessary to incorporate the 
route choice between toll roads and urban streets ${ }^{1}$. Section 2 presents the basic model. Section 3 formulates the problem to obtain the second-best congestion pricing, and specifies alternative schemes. Section 4 presents the results of a case study and discusses the relative effects of alternative systems. Section 5 concludes the paper.

\section{The model}

Urban areas are divided into $I$ discrete zones, and trips are originated from and destined to zone centroids. We focus only on road transportation. The network consists of nodes and links where some nodes represent the zone centroids. We use $A$ to define the set of links in the network, in which $x_{a}$ is the traffic volume of link $a(a \in A)$. Demand for car trips is elastic, and the demand function is given by $D_{r s}\left(C_{r s}\right)$, where $C_{r s}$ is the cost for a trip from $r$ to $s$. There are several routes between $r$ and $s$, and trip cost is defined as the sum of monetary cost and time cost, as follows

(1) $c_{r s}^{j}=w t_{r s}^{j}+\tau_{r s}^{j}$

where $t_{r s}^{j}$ and $\tau_{r s}^{j}$ are respectively trip time and monetary cost (=toll) for $j$-th route between $r$ and $s . w$ is the opportunity cost of trip time. A trip maker chooses the route so as to minimize the trip cost, thus trip cost included in the demand function is $C_{r s}=\operatorname{Min}_{j}\left\{c_{r s}^{j}\right\}$. Trip time $t_{r s}^{j}$ is the sum of times required to pass through the links on the $j$-th route, as follows

(2) $t_{r s}^{j}=\sum_{a} \delta_{\text {ars }}^{j} t_{a}\left(x_{a}\right)$

where $\delta_{\text {ars }}^{j}$ is a 0 -1 variable taking the value one if the link $a$ is included on the $j$-th path for O-D pair $r s$, and zero otherwise. $t_{a}\left(x_{a}\right)$ is an increasing function with respect to link flow, $x_{a}$, which represents the time required to pass through the link $a$. Link flow is the sum of O-D trips using that link

(3) $x_{a}=\sum_{r} \sum_{s} \sum_{j} \delta_{a r s}^{j} f_{r s}^{j}$

where $f_{r s}^{j}$ is the path flow that is the number of trips on the $j$-th route of O-D pair $r s$. Likewise, monetary cost is the sum of tolls for links on the path,

(4) $\tau_{r s}^{j}=\sum_{a} \delta_{a r s}^{j} \tau_{a}$

where $\tau_{a}$ is the toll for link $a$.

\footnotetext{
${ }^{1}$ A recent paper by de Palma and Lindsey (2002) considers the problem of finding the optimal number and locations of a tolled road in a radial network. Although they provide interesting policy implications, the analysis is based on an artificial setting in that all residents are located on a single circumference (same distance from the center).
} 
Suppose that the number of O-D trips is given by $Q_{r s}$. User equilibrium of route choice is attained when no driver has an incentive to change the route. This is Wardrop's first principle that the trip costs in all routes actually used are equal and less than those which would be experienced by a single vehicle on any unused route. Let $R_{r s}$ be the set of available routes between $r$ and $s$. Then user equilibrium requires that the following condition holds for all $j \in R_{r s}$.

$$
\begin{aligned}
& f_{r s}^{j}>0 \Rightarrow c_{r s}^{j}=C_{r s}^{*} \\
& f_{r s}^{j}=0 \Rightarrow c_{r s}^{j} \geq C_{r s}^{*}
\end{aligned}
$$

where $C_{r s}^{*}$ is trip cost in user equilibrium of route choice. The above conditions are equivalent to the following:

(5a) $c_{r s}^{j}-C_{r s}^{*} \geq 0$

$f_{r s}^{j}\left(c_{r s}^{j}-C_{r s}^{*}\right)=0$

(6) $f_{r s}^{j} \geq 0$

Conservation of flows requires that the following relation holds:

(7)

$Q_{r s}=\sum_{j \in R_{r s}} f_{r s}^{j}$

Each individual will make a trip as long as private marginal benefit exceeds trip cost. The private marginal benefit of the trip from $r$ to $s$ is given by the inverse demand function, $D_{r s}^{-1}\left(Q_{r s}\right)$ and trip cost is given by $C_{r s}^{*}$, which is equalized regardless of routes in the user equilibrium of route choice. Thus, the equilibrium number of O-D trips $Q_{r s}$ is determined so that the following relation holds:

$$
D_{r s}^{-1}\left(Q_{r s}\right)=C_{r s}^{*}
$$

Network equilibrium under elastic demand is characterized by the solution to the equation system (5)-(8), which is the combination of O-D trips, $Q_{r s}$, O-D trip costs, $C_{r s}^{*}$, link flows, $x_{a}$, and path flows, $f_{r s}^{j}$. Although path flows are not uniquely determined, it does not matter because link flows give sufficient information to evaluate the traffic patterns and level of economic welfare.

We consider the case of no-toll equilibrium as the benchmark, which is obtained by solving the above equations by setting $\tau_{a}=0$, for all $a \in A$ in (4). 
On the other hand, socially efficient road use is obtained by maximizing the social surplus as follows.

(9) $\underset{f_{r s}^{\prime}}{\operatorname{Max}} \sum_{r} \sum_{s} \int_{0}^{Q_{r s}} D_{r s}^{-1}(z) d z-w \sum_{a} t_{a}\left(x_{a}\right) x_{a}$

subject to (6) and (7).

First order conditions for optimization are

$$
\begin{aligned}
& D_{r s}^{-1}\left(Q_{r s}\right)-w \sum_{a} \delta_{a r s}^{j}\left\{t_{a}\left(x_{a}\right)+t_{a}^{\prime}\left(x_{a}\right) x_{a}\right\} \leq 0 \\
& {\left[D_{r s}^{-1}\left(Q_{r s}\right)-w \sum_{a} \delta_{a r s}^{j}\left\{t_{a}\left(x_{a}\right)+t_{a}^{\prime}\left(x_{a}\right) x_{a}\right\}\right] f_{r s}^{j}=0}
\end{aligned}
$$

where the $t_{a}^{\prime}\left(x_{a}\right) x_{a}$ that is shown in the bracket of LHS represents the congestion externalities that an additional flow on the link $a$ imposes on all vehicles using the link. Eq. (10) is consistent with the general rule for social efficiency: social marginal benefit should be equal to (less than) the social marginal cost for used routes (for unused routes). Hereafter we use the expression "first-best" to denote the most efficient road use.

Comparing the above conditions with equilibrium conditions (5)-(8), we see that the first-best situation is decentralized if the toll at each link is determined in the following way

$$
\tau_{a}=w t_{a}^{\prime}\left(x_{a}\right) x_{a}
$$

That is, the toll of each link should be equal to the congestion externality. Implementing this tolling scheme is practically infeasible since imposing tolls on all links requires prohibitive cost. This case does not provide an alternative policy but serves as a reference point for evaluating the performance of second-best pricing policies.

\section{Second-best pricing policies}

\subsection{General problem}

Suppose that tolls are levied on only a small portion of links in the network, due to social and technological constraints. The second-best pricing policy is characterized as the set of tolls for a subset of links in the network, which maximizes the social surplus subject to network equilibrium conditions. The problem to be solved is generally formulated as follows,

$$
\operatorname{Max}_{\tau} \sum_{r} \sum_{s} \int_{0}^{Q_{r s}(\boldsymbol{\tau})} D_{r s}^{-1}(z) d z-w \sum_{a \in A} t_{a}\left(x_{a}(\boldsymbol{\tau})\right) x_{a}(\boldsymbol{\tau})
$$

subject to

(13a) $\tau_{a} \geq 0$, for $a \in H$, 


$$
\tau_{a}=0, \text { for } a \notin H
$$

where $\tau=\left(\tau_{1}, \tau_{2}, \ldots, \tau_{L}\right)$, and $H(H \subset A)$ is the set of links where tolls are levied. In this paper, locations of the tolled links are given exogenously. The formulations $Q_{r s}(\tau), x_{a}(\tau)$ are the solutions to the equation system (5)-(8), under given $\tau$. Thus these are expressed as functions of $\boldsymbol{\tau}$. The optimal value of the social surplus obtained by solving the above problem must be smaller than that obtained by the first-best. If $H=A$, the solution to the above problem must coincide with the first-best. Below we describe the alternative pricing systems, each of which is a special case of the above problem.

\subsection{Single cordon pricing}

The single cordon pricing system is designed as follows: each vehicle is charged a fixed toll when it passes through the specified cordon surrounding the central area of a city. In this case, the set of links crossing the cordon line becomes $H$, the set of tolled links. A uniform toll equal to $\bar{\tau}^{C}$ is applied to all links in $H$. The problem of obtaining optimal single cordon pricing is formulated as follows,

$$
\operatorname{Max}_{\bar{\tau}^{C}} \sum_{r} \sum_{s} \int_{0}^{Q_{r s}(\boldsymbol{\tau})} D_{r s}^{-1}(z) d z-w \sum_{a \in A} t_{a}\left(x_{a}(\boldsymbol{\tau})\right) x_{a}(\boldsymbol{\tau})
$$

subject to

(15a) $\tau_{a}=\bar{\tau}^{C}$, for $a \in H$,

(15b) $\tau_{a}=0$, for $a \notin H$

\subsection{Multiple cordon pricing}

Suppose that there are $M$ cordon lines like concentric rings, and they are numbered from the center as $1,2, \ldots, M$. The set of tolled link, $H$, has $M$ subsets, $h_{m}, m=1,2, \ldots M$, each of which corresponds to the set of links crossing the $m$-th cordon line. A uniform toll, $\bar{\tau}^{C_{m}}$, is applied for all links in $h_{m}$. For the problem of multiple cordon pricing, the control variable becomes $M$ dimensional, that is, $\bar{\tau}^{C_{m}}, m=1,2, \ldots, M$. Thus, the constraints (13) are rewritten as follows

$$
\tau_{a}=\bar{\tau}^{C_{m}}, \quad \text { for } a \in h_{m}, \quad \bigcup_{m=1}^{M} h_{m}=H
$$

(16b) $\tau_{a}=0, \quad$ for $a \notin H$

\subsection{Uniform pricing on existing toll roads}

This is similar to the current system of levying a toll equal to $700 \mathrm{Yen}$ at on-ramps to the toll roads. The current toll level is determined so that toll revenue covers expenses including maintenance cost and redemption of construction cost, so it is not intended to control congestion. We search for the optimal uniform toll level to minimize the loss of congestion 
in the road network as a whole. It is interesting to see whether the optimal toll is higher or lower than the current toll level. Our network includes links representing the on-ramps to the toll roads at which the uniform toll is levied. Therefore, the problem to be solved is formally equivalent to (14)(15) above if the set of tolled links, $\mathrm{H}$, are replaced by on-ramps.

\subsection{Zone pricing on existing toll roads}

The toll road network is divided into several zones, and toll equal to $\bar{\tau}_{m}^{H}$ is levied to vehicles using the road sections within the domain of $m$-th zone. This toll is charged when a vehicle uses a link representing an on-ramp in the corresponding zone, or a link crossing the boundary of the zone on toll roads. The constraints of the problem are described as in (16), that for multiple cordons, but the set of tolled links, $h_{m}$, is given according to the above definition.

\section{Case study of Osaka metropolitan area}

\subsection{Settings}

The model is applied to the Osaka Metropolitan Area, which consists of 36 zones as shown in Figure 1. Zones 1-27 belong to the jurisdiction of Osaka City, of which Zones 1-3 are identified as CBD.

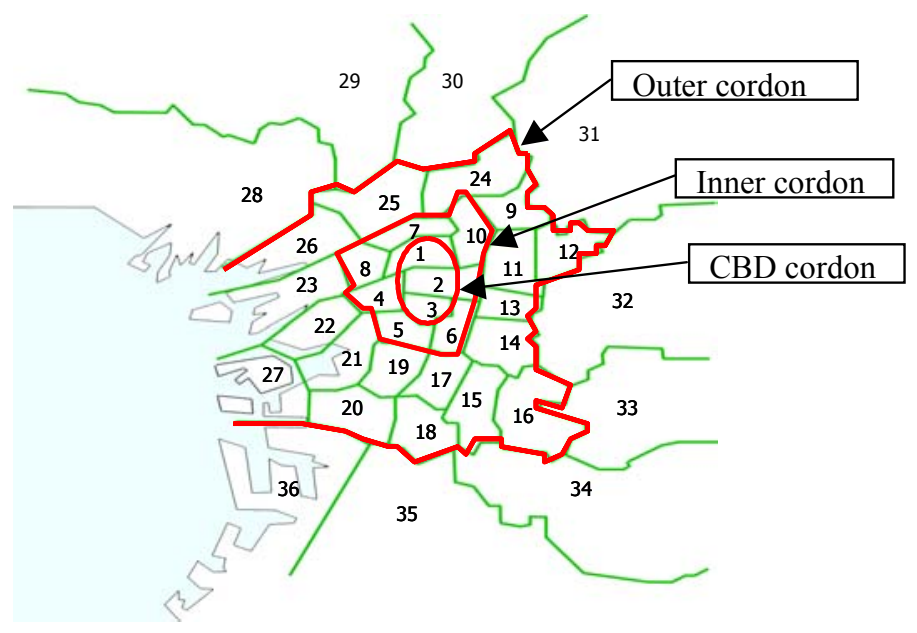

Figure 1: Case study area 


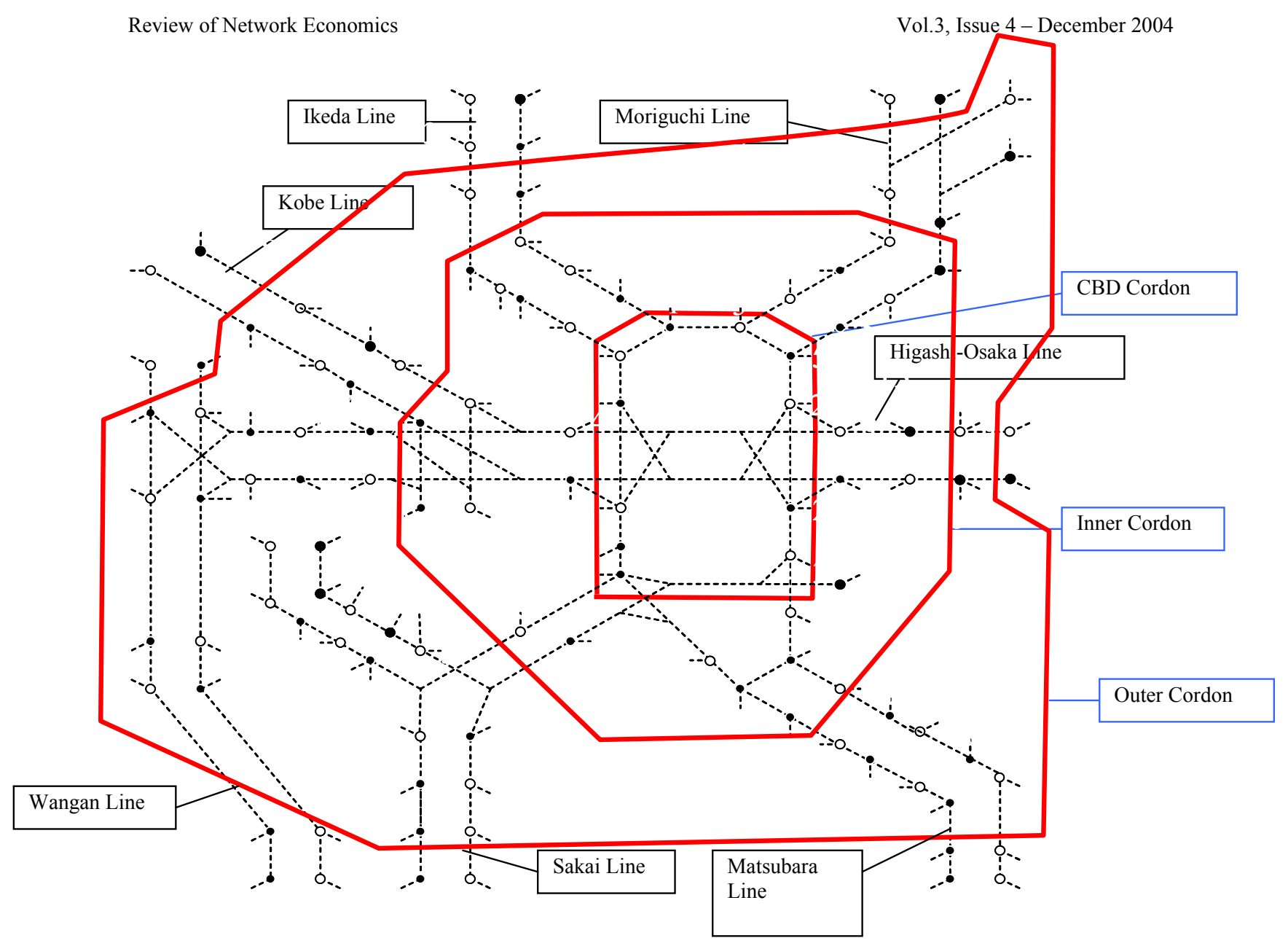

Figure 2: Toll road network and locations of cordon lines

This area has networks of toll roads and urban streets. We construct a network with 241 nodes and 630 links, of which 276 links belong to toll roads. Figure 2 illustrates the toll road network ${ }^{2}$. The toll roads were constructed and are operated by the Hanshin Expressway Public Corporation. As shown in Figure 2, the toll road network has a loop line and 7 radial lines, which currently extends $233.8 \mathrm{~km}$ in total length. About 890,000 vehicles use the toll roads on average per day. Three cordon lines to be examined later are indicated in the figures. The relations between the cordon lines in Figures 1 and 2 are evident.

The link travel time function is specified as

$$
t_{a}(x)=f_{a}\left\{1+v\left(\frac{x_{a}}{K_{a}}\right)^{\gamma}\right\}
$$

where $f_{a}$ is free-flow travel time for link $a, K_{a}$ is traffic capacity of link $a$. We adopt the parameter values, $v=0.48, \gamma=2.82$, proposed in the manual published by the Japan Society of Civil Engineers.

We specify the form of the trip demand function as

\footnotetext{
${ }^{2}$ We do not include the urban street network in the figure to avoid complication.
} 


$$
D_{r s}\left(C_{r s}\right)=\alpha \cdot n_{r} \cdot n_{s}^{\theta_{S}} \cdot \exp \left(-\beta \cdot C_{r s}\right)
$$

where $n_{r}, n_{s}$ are populations of zones $r$ and $s$, respectively, and $\alpha, \beta, \theta_{s}$ are parameters to be estimated empirically below.

We use the data on O-D trips from the Road Census Survey in Japan in 1994. Trip cost data as an independent variable in the parameter estimation are obtained by the following formula

$$
C_{r s}=\sum_{a \in A_{r s}^{*}}\left\{w t_{a}(\mathscr{\ell})+\mathscr{q} \%\right)
$$

where $\ell \frac{q}{q} \%$ are observed link flows and the current road toll. $A_{r s}^{*}$ is the set of links on the shortest path between $r$ and $s$ based on trip cost. We assume that the value of travel time, $w$, is equal to 60 Yen per minute, which is based on empirical estimations in Japan. The result of parameter estimation for trip demand function is given as follows:

$$
\begin{aligned}
& \alpha=0.000024 \quad(15.0503) \\
& \theta_{S}=0.6055 \quad(10.2505) \\
& \beta=-0.00074(-24.8606)
\end{aligned} \quad R^{2}=0.5430
$$

Figures in the parentheses are T statistics.

\subsection{No-toll equilibrium and first-best}

Table 1 shows the summary of solutions under no-toll equilibrium, the first-best optimum, and current toll system. The first-best optimum is attained when the toll at each link is set equal to the congestion externality. Note that the congestion externality for one trip increases with distance traveled. The congestion toll discourages long distance trips, so the average travel distance decreases from $9.52 \mathrm{~km}$ to $8.62 \mathrm{~km}$. Two forces act to decrease the average travel time: reductions in congestion levels and travel distances. On average, users pay 672 Yen for a trip of $8.6 \mathrm{~km}$. The gain from the first-best policy is 595 Million Yen, which is the difference in the values of social surplus between the first-best and the no-toll cases. This value is interpreted as the economic loss due to congestion for one day, since society loses this amount in the no-toll case by not internalizing congestion externalities. This value is also considered as the maximal gain that society may attain by controlling congestion. Hereafter we evaluate the second best policies by relative gains compared with this maximal gain, as follows

Relative gain $=\frac{S S^{* *}-S S^{*}}{S S^{O}-S S^{*}}$

where $S S^{*}, S S^{O}, S S^{* *}$ are respectively the values of social surplus under the no-toll equilibrium, the first-best, and the second-best policy. 
The current toll system improves the value of social surplus by 267 Million Yen, for which the relative gain according to the above formula is equal to $44.8 \%$. The current system contributes to the reduction of congestion more effectively than expected.

\begin{tabular}{lrrr}
\hline & No toll & First-best & Current toll \\
\hline Total trips (Vehicles) & $2,352,145$ & $1,919,533$ & $2,244,128$ \\
Total travel distance (Vehicles*km) & $22,381,331$ & $16,555,751$ & $20,778,071$ \\
Total travel time (Vehicles*hours) & $1,183,696$ & 677,124 & $1,039,374$ \\
Average travel distance (km) & 9.52 & 8.62 & 9.26 \\
Average travel time (minutes) & 30.2 & 21.2 & 27.8 \\
Average toll payment (Yen) & 0 & 672 & 151 \\
Change in consumer surplus (Million Yen) & & -696 & -71 \\
Toll revenue (Million Yen) & 0 & 1,291 & 338 \\
Gain from tolling (Million Yen) & & 595 & 267 \\
\hline
\end{tabular}

Table 1: No-toll equilibrium, first-best optimum, and current toll system

\subsection{Cordon pricing}

We specify three cordon lines as shown in Figures 1 and 2. We first examine the single cordon pricing whereby a uniform toll is charged at one of three cordons. The optimal toll is obtained by one-dimensional search in which the increment is 100 Yen. For example, Figure 3 depicts the relation between toll level and social surplus for the Outer Cordon case. The problem has a well-behaved structure in that the optimal solution is uniquely determined.

Table 2 shows the results for three alternative cordon-pricing systems. The optimal toll is larger as the cordon is located farther from the center. The gain from tolling is maximized in the Outer Cordon case. In this case, the optimal toll is 700 Yen, and the relative gain is $65.5 \%$.

We next examine three-layered cordon pricing under which tolls are charged at three cordon lines. The optimal combination of tolls at three cordons is obtained by a grid search where toll levels at each cordon are varied for the range of 0-2000 Yen with increments of 100 Yen; the total number of combinations is $20^{3}=8000$. Table 4 shows the results for the top 5 cases that are ranked according to the values of gain from tolling. The values of gain from tolling are similar among 5 cases, so are the toll levels. For the optimal combination, tolls are 200 Yen at the CBD cordon, 200 Yen at the Inner cordon, and $600 \mathrm{Yen}$ at the Outer Cordon. 1000 Yen is charged in total to travel from outside Osaka city to the CBD by car. The gain from optimal three-layered cordon pricing is $76.8 \%$ of the maximal gain, which is good performance. 


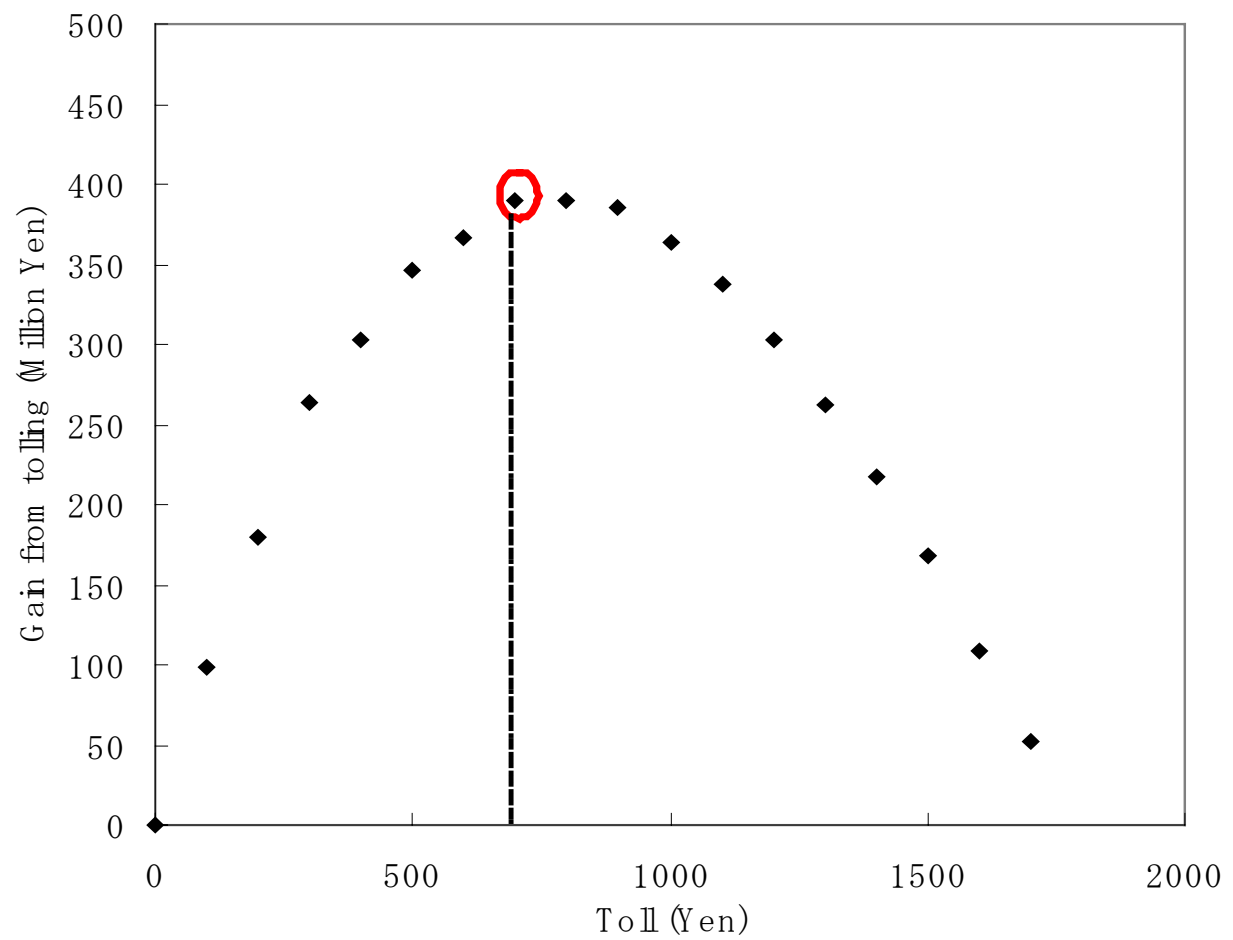

Figure 3: Optimal toll for outer cordon

\begin{tabular}{lrrrr}
\hline & No toll & CBD Cordon & Inner Cordon & Outer Cordon \\
\hline Optimal cordon toll & & 300 & 500 & 700 \\
Total trips (Vehicles) & $2,352,145$ & $2,202,034$ & $2,070,364$ & $2,068,861$ \\
Total travel distance (Vehicles*km) & $22,381,331$ & $20,461,383$ & $18,678,035$ & $17,877,502$ \\
Total travel time (Vehicles*hours) & $1,183,696$ & $1,043,001$ & 913,443 & 809,984 \\
Average travel distance (km) & 9.5 & 9.29 & 9.02 & 9 \\
Average travel time (minutes) & 30.2 & 28.4 & 26.5 & 23 \\
Average toll payment (Yen) & 0 & 148 & 276 & 367 \\
Change in consumer surplus (Million Yen) & & -160 & -314 & -369 \\
Toll revenue (Million Yen) & 0 & 325 & 571 & 760 \\
Gain from tolling (Million Yen) & & 165 & 258 & 390 \\
Relative gain & & $27.74 \%$ & $43.26 \%$ & $65.58 \%$ \\
\hline
\end{tabular}

Table 2: Results for three alternative cordon-pricing systems 


\begin{tabular}{lrrrrr}
\hline & 1 & 2 & 3 & 4 & 5 \\
\hline Toll at CBD Cordon (Yen) & 200 & 100 & 200 & 200 & 100 \\
Toll at Inner Cordon (Yen) & 200 & 200 & 200 & 100 & 100 \\
Toll at Outer Cordon (Yen) & 600 & 600 & 500 & 600 & 700 \\
Total trips (Vehicles) & $1,876,692$ & $1,925,830$ & $1,916,118$ & $1,936,784$ & $1,947,489$ \\
Total travel distance (Vehicles*km) & $15,624,439$ & $16,223,493$ & $16,194,679$ & $16,344,811$ & $16,364,955$ \\
Total travel time (Vehicles*hours) & 677,818 & 712,530 & 717,560 & 721,810 & 716,085 \\
Average travel distance (km) & 8.33 & 8.42 & 8.45 & 8.44 & 8.40 \\
Average travel time (minutes) & 21.7 & 22.2 & 22.5 & 22.4 & 22.1 \\
Average toll payment (Yen) & 552 & 511 & 510 & 499 & 494 \\
Change in consumer surplus (Million Yen) & -578 & -530 & -524 & -514 & -511 \\
Toll revenue (Million Yen) & 1,036 & 984 & 977 & 967 & 962 \\
Gain from Tolling (Million Yen) & 458 & 454 & 453 & 453 & 450 \\
Relative gain & $76.87 \%$ & $76.31 \%$ & $76.11 \%$ & $76.07 \%$ & $75.67 \%$ \\
\hline
\end{tabular}

Table 3: Results for top 5 of three-layered cordon pricing

\subsection{Congestion pricing for existing toll roads}

We compute the optimal uniform toll for the Hanshin Expressway, where a uniform toll of 700 Yen is currently levied. As shown in Table 4, the optimal uniform toll is 900 Yen, which is higher than the current toll.

Next, we examine zone pricing for toll roads. The toll road network is divided into two zones, that is, inner zone and outer zone, and different tolls are levied for the use of toll roads within each zone. We consider three alternative plans concerning the division of zones, each of which uses one of the three cordon lines shown in the previous section as the boundary between inner and outer zones. Zone System A in Table 4 uses CBD cordon as the boundary, Zone System B uses the Inner Cordon, and Zone System C uses the Outer Cordon. Zone System $\mathrm{C}$ attains the largest gain, which is $53.8 \%$ of the maximal gain. Gains from congestion pricing for existing toll roads are smaller than those from the cordon pricing. This result is reasonable because the extent of trips controlled by pricing is smaller; it is possible to avoid payment in the case of pricing only at toll roads while cordon pricing captures all trips entering the central area. Note that the loss in consumer surplus under pricing for toll roads is much smaller than that under cordon pricing. For example, cordon pricing at the Inner Cordon shown in Table 2 and the Zone System A shown in Table 4 attain similar total welfare gains. However, losses in consumer surplus under cordon pricing and pricing for toll roads are respectively -314 and -95 (million Yen), which is a big difference. Toll revenue with the Inner Cordon is much larger (514 versus 386 million Yen). 


\begin{tabular}{|c|c|c|c|c|}
\hline & Uniform toll & Zone System A & Zone System B & Zone System C \\
\hline Uniform toll (Yen) & 900 & & & \\
\hline Toll for Inner Zone (Yen) & & 600 & 500 & 600 \\
\hline Toll for Outer Zone (Yen) & & 200 & 200 & 500 \\
\hline Total trips (Vehicles) & $2,182,796$ & $2,216,391$ & $2,228,534$ & $2,202,561$ \\
\hline Total travel distance (Vehicles*km) & $19,816,894$ & $20,232,568$ & $19,771,329$ & $19,243,220$ \\
\hline Total travel time (Vehicles*hours) & 991,673 & $1,009,733$ & 991,471 & 957,026 \\
\hline Average travel distance $(\mathrm{km})$ & 9.08 & 9.13 & 8.87 & 8.74 \\
\hline Average travel time (minutes) & 27.3 & 27.3 & 26.7 & 26.1 \\
\hline Average toll payment (Yen) & 185 & 174 & 182 & 213 \\
\hline Change in consumer surplus (Million Ye: & -128 & -95 & -102 & -149 \\
\hline Toll revenue (Million Yen) & 403 & 386 & 405 & 469 \\
\hline Gain from tolling (Million Yen) & 275 & 292 & 303 & 321 \\
\hline Relative gain & $46.18 \%$ & $49.00 \%$ & $50.94 \%$ & $53.87 \%$ \\
\hline
\end{tabular}

Table 4: Congestion pricing for existing toll roads

\section{Conclusion}

This paper examines the effects of alternative congestion pricing systems, cordon pricing and congestion pricing for existing toll roads, using the network equilibrium model developed for the Osaka Metropolitan Area, Japan. Cordon pricing is more effective in reducing the total efficiency loss from traffic congestion. On the other hand, pricing for existing toll roads keeps the loss in consumer surplus low to attain the same level of efficiency gain as the cordon pricing. The difference in efficiency between cordon pricing and pricing for toll roads could be reduced by refining the design of the pricing system for toll roads, such as increasing the number of zones, differentiating the toll schedules by O-D pairs, etc. These extensions require developments of computing methods to obtain the optimal combination of tolls with a large number of dimensions, which is an important task for future research.

\section{$6 \quad$ References}

de Palma, A. and R. Lindsey (2002) "Road Pricing for a Monocentric City with a Radial Network," Paper for presentation at the $49^{\text {th }}$ North American Meetings of the Regional Science Association International, San Juan, Puerto Rico.

Ho, H. W., S. C. Wong, H. Yang, B. P. Y. Loo (2003) "Cordon-based Congestion Pricing in a Continuum Traffic Equilibrium System," Presentation at International Conference on the Theory and Practice of Congestion Charging, London.

Mun, S., K. Konishi and K. Yosikawa (2003a) "Optimal Cordon Pricing," Journal of Urban Economics, 54: 21-38. 
Mun, S., K. Konishi and K. Yosikawa (2003b) "Optimal Cordon Pricing for a Non-Monocentric City," Paper for presentation at International Symposium on the Theory and Practice of Congestion Charging, Imperial College London.

May, A. D., D. S. Milne (2000) "Effects of Alternative Road Pricing Systems on Network Performance," Transportation Research, Part A, 34: 407-436.

Santos, G., D. Newbery, L. Rojey (2001) "Static vs. Demand Sensitive Models and the Estimation of Efficient Cordon Tolls: An Exercise for Eight English Towns," Transportation Research Record 1747: 44-50.

Sumalee, A. (2004) "Optimal Road User Charging Cordon Design: A Heuristic Optimization Approach," Journal of Computer-Aided Civil and Infrastructure Engineering 19: 377-392.

Verhoef, E. T. (2002) "Second-best Congestion Pricing in General Networks: Heuristic Algorithms for Finding Second-best Optimal Toll Levels and Toll Points," Transportation Research, Part B, 36: 707-729.

Verhoef, E. T., P. Nijkamp, P. Rietveld (1996) "Second-best Congestion Pricing: The Case of an Untolled Alternative," Journal of Urban Economics, 40: 279-302.

Zhang, X., H. Yang (2004) "The Optimal Cordon-based Network Congestion Pricing Problem," Transportation Research, Part B, 38: 517-537.

Japan Society of Civil Engineers (2003) Theory and Application of Road Travel Demand Forecasting (in Japanese). 